\title{
ВЗАИМОСВЯЗЬ СЕМЬИ И СЕМЕЙНЫХ ОТНОШЕНИЙ С ЗАБОЛЕВАНИЕМ ЖЕЛУДОЧНО-КИШЕЧНОГО ТРАКТА У ДЕТЕЙ 8-12 ЛЕТ
}

\author{
(С) Фетисова А.С., Хмелевская И.Г.
}

\author{
Кафедра педиатрии Курского государственного медицинского университета, Курск \\ E-mail: kypck046@,bk.ru
}

\begin{abstract}
В статье представлены результаты изучения особенностей семьи и семейных отношений у детей с функциональной диспепсией. Личность ребенка формируется под влиянием множества факторов. При этом особое значение имеют характер семейных отношений и состояние соматического здоровья ребенка. В ходе статистического и качественного анализа были получены результаты, указавающие на взаимосвязь семейной адаптации, семейной сплоченности и статуса семьи с заболеваниями желудочно-кишечного тракта (функциональная диспепсия). Полученные результаты обосновывают необходимость проведения психокоррекционной работы с детьми, страдающими функциональной диспепсией, направленной на гармонизацию социально-психологического профиля с учетом выявленных его особенностей.
\end{abstract}

Ключевые слова: функциональная диспепсия, характер семейных отношений, семейная система, сплоченность, адаптация.

\section{THE INTERRELATION OF FAMILY AND FAMILY RELATIONS WITH DISEASES OF DIGESTIVE TRACT IN 8-12 YEAR-OLD CHILDREN \\ Fetisova A.S., Khmlevskaya I.G. \\ Pediatrics Department of Kursk State Medical University, Kursk}

The article represents the results of studying family and family relations of children suffering from functional dyspepsia. The development of children's personality is influenced by a lot of factors, including the nature of family relationships and somatic health status of a child. The statistical and qualitative analysis of the received results indicates interrelation of family adaptation, family unity and the status of a family with a digestive tract disease (functional dyspepsia). The studies prove the need for psychocorrecting work with children suffering from functional dyspepsia aimed to harmonize social and psychological profile taking into account its features revealed.

Keywords: functional dyspepsia, character of family relations, family system, unity, adaptation.

Актуальность исследования обусловлена противоречием между необходимостью учета социально-психологического фактора в возникновении психосоматических заболеваний, на которую указывали 3. Фрейд, П. Кристиан, М. Рад, Д. Коннор, Ф. Дейч, П. Сифнеос, Д.В. Винникотт, Ф. Данбар, Ф. Александер $[1,5,7,17]$, и недостаточной разработанностью данной проблемы в современных исследованиях, особенно касающихся влияния семьи и семейных отношений на возникновение и течение заболеваний желудочно-кишечного тракта у детей. До настоящего времени в этиологии и патогенезе заболеваний желудочно-кишечного тракта роль семьи и семейных отношений остается недостаточно изученной, довольно часто встречаются неудовлетворительные результаты лечения, растет частота обострений.

Теоретическое осмысление проблемы взаимосвязи социально-психологических условий с возникновением заболеваний началось в начале $\mathrm{XX}$ века с трудов 3. Фрейда в рамках исследований, посвященных психосоматической проблематике. 3. Фрейдом была разработана концепция психосоматических заболеваний и механизм конверсии эмоционального конфликта на соматический уровень [17]. Понимание возникновения психосоматических заболеваний было существенно дополнено концепцией соматического языка Ф. Дейч, концепцией алекситимии П. Сифнеос, концепцией симбиоза в первичных отношениях матери и ребенка Д.В. Винникота [7].

Возникновение соматических расстройств под влиянием психических факторов, вытесненную склонность к самоповреждению изучала Ф. Данбар. Характер системы отношений и типа ролевого поведения как условия возникновения психосоматической патологии; взаимосвязь личностных особенностей с наличием язвенной болезни (фрустрация потребности в любви, выраженность агрессивно-враждебной тенденции) изучал Ф. Александер [1]. Вопросами агрессивности и злобы занимался Б. Любан-Плоцца. Б. Бройтигам, П. Кристиан, М. Рад исследовали типы личности больных с различными заболеваниями [5]. Данной проблематике посвящен целый ряд работ отечественных исследователей: влияниие личности на состояние здоровья (Л.В. Бороздина, Н.Д. Былкина-Михеева) [3]; исследование роли психосоциальных влияний в возникновении язвенной болезни и предъязвенных состояний $\mathrm{y}$ детей 
Л.И. Тульчиной; взаимосвязь заболеваний желудочно-кишечного тракта с соматическим состоянием до заболевания (наследственность, беременность), личностью больного, семейными условиями Д.Н. Исаева, А.А. Лифинцевой [10; 11]; исследование взаимосвязи семейных оценочных отношений, самооценки и тревожности с функциональной диспепсией $\mathrm{y}$ детей [16].

Большинство исследователей изучали отдельные взаимосвязи болезни с личностными особенностями и социально-психологическими условиями. Эти исследования проведены в психоаналитической традиции и рассматривают психосоматический аспект различных заболеваний. Практически не встречается работ комплексного исследования взаимосвязи семьи, семейных отношений, личности ребенка и его заболевания с акцентом на социально-психологическом аспекте этой проблемы.

Согласно Э.Г. Эйдемиллеру, семейно-обусловленные психотравмирующие переживания являются тем фактором, который способствует трансформации нарушения жизнедеятельности семьи в нервно-психическое или соматическое расстройство индивида [19].

Разнообразие подходов исследования к пониманию семьи позволяет выявить специфику семьи и ее влияние на семейные отношения. Отечественные и зарубежные психологи рассматривали семью в различных аспектах: семья может развиваться как малая группа (Г.М. Андреева, A.B. Петровский) [2], как общность (Б.Д. Парыгин, В.И. Слободчиков, Е.И. Исаев), как субъект целенаправленной активности (А.И. Донцов, А.Л. Журавлев, А.С. Чернышев, С.В. Сарычев, К.М. Гайдар) [9, 18], как циркулярная модель (Д.Х. Олсон) и как система (М. Боуэн, С. Минухин, В. Сатир) [4, 12, 15]. В данных исследованиях авторы ставят различные акценты. В понятии социальная группа фиксируется аспект самого функционирования некоторого сообщества людей, объединенных общими целями. В понятии общность в большей степени акцент ставится на результат этого функционирования - социальное переживание (духовная солидарность, чувство мы, взаимопонимание). В понятии семьи как субъекта целенаправленной активности делается акцент на совместные формы активности группы. В циркулярной модели семьи Д.Х. Олсона подчеркивается способность семейной системы адаптироваться к изменениям ситуации и стрессам. Тип семейной структуры определяется двумя основными параметрами (семейная сплоченность и семейная адаптация) и одним дополнительным (коммуникация). К конструктивным типам семей- ной сплоченности относятся разделенный и связанный типы, к неконструктивным - разобщенный и сцепленный. К конструктивным типам семейной адаптации относятся гибкий и структурный типы, к неконструктивным - хаотичный и ригидный. Для сбалансированной семьи характерно сочетание конструктивных типов семейной сплоченности и адаптации, для несбалансированной семьи характерно сочетание неконструктивных типов семейной сплоченности и адаптации, остальные сочетания типов семейных сплоченности и адаптации относятся к среднесбалансированным семьям [20].

Данные подходы к семье тесно взаимосвязаны: различным теоретическим языком описывают целостность функционирования и взаимосвязанность между элементами коллективного субъекта (А.Л. Журавлев), системы (Д.Х. Олсон, М. Боуэн, С. Минухин, В. Сатир) $[4,9,12,15]$. Интеграция подходов к семье как к коллективному субъекту и как к системе помогает лучше понять особенности семейных отношений и их взаимосвязь с семьей как с целостностью. Понятия организованность группы А.С. Чернышева и надежность группы С.В. Сарычева помогают раскрыть особенности взаимосвязи семьи, семейных отношений, личности ребенка и его болезни. Авторы рассматривают организованность и надежность группы как интегральные характеристики, которые проявляются в ситуации неопределенности, напряженных и экстремальных ситуациях. К этим ситуациям можно отнести семейные отношения в условиях болезни ребенка.

Характер семейных отношений отражает уровень функционирования группы в целом и самочувствия личности в рамках семьи (В.Н. Мясищев, А.В. Петровский, Э.Г. Эйдемиллер, И.В. Добряков, И.М. Никольская, И.М. Балинский, А.И. Захаров, А.Я. Варга, В.В. Сто-лин, С. Соловейчик, П.Ф. Лесгафт, В. Сатир, М. Боуэн, С. Минухин) $[6,8,12,13,14,15,19]$.

Таким образом, выявление особенностей взаимосвязи функционирования семьи в целом, характера семейных отношений, особенностей личности родителей и ребенка с функциональной диспепсией помогут разработать профилактические корригирующие мероприятия по предупреждению и лечению заболеваний желудочно-кишечного тракта у детей.

Цель исследования - выявить взаимосвязь семьи, семейных отношений с возникновением и течением заболеваний желудочно-кишечного тракта (функциональной диспепсии) и разработать рекомендации по оптимизации профилактики и лечения данного заболевания с учетом особенностей семьи и семейных отношений. 


\section{МАТЕРИАЛЫ И МЕТОДЫ ИССЛЕДОВАНИЯ}

Эмпирической базой исследования выступили педиатрическое отделение ОБУЗ «Городская больница № 3» г. Курска и средняя общеобразовательная школа с углубленным изучением отдельных предметов № 7 им. А.С. Пушкина г. Курска. В исследовании приняли участие 224 испытуемых (дети 8-12 лет). Используя принцип рандомизации, были сформированы 2 группы: экспериментальная (дети 8-12 лет, страдающие функциональной диспепсией) 112 человек и контрольная (здоровые дети 8-12 лет) - 112 человек.

Теоретические методы исследования - комплексный теоретический анализ литературы по проблеме исследования, сравнительно-сопоставительный анализ, систематизация и обобщение научных представлений, понятий, результатов теоретических и эмпирических исследований.

В качестве эмпирических методов в исследовании использовался метод формализованного наблюдения, особенности функционирования семьи, характер семейных отношений оценивали с помощью опросника «Шкала семейной адаптации и сплоченности» FACES-3 (Авторы: Олсон, Портнер, Лави; адаптирован М. Перре) [20].

Для анализа полученных данных проводили их статистическую обработку, применяя качественный анализ, методы математической статистики (критерий $\chi^{2}$ Пирсона, критерий КрускалаУоллиса). Все расчеты проводились с использованием статистического пакета «Statistica 6.0.» и «Microsoft Office Excel».

\section{РЕЗУЛЬТАТЫ ИССЛЕДОВАНИЯ И ИХ ОБСУЖДЕНИЕ}

В ходе статистического и качественного анализа данных взаимосвязи семейной адаптации, семейной сплоченности и статуса семьи с заболеваниями желудочно-кишечного тракта (функциональная диспепсия) были получены следующие результаты. По опроснику «Шкала семейной адаптации и сплоченности» FACES-3 мы получили достоверные различия в экспериментальной и контрольной группах по шкале семейная адаптация (табл. 1) и семейная сплоченность (табл. 2).

В группе больных детей чаще встречается хаотичный тип адаптации, что свидетельствует о повышенной чувствительности семейной системы к изменениям; в группе здоровых детей чаще встречаются гибкий и структурный типы семейной адаптации, которые характеризуют семейную систему как более стабильную. Различия достигают уровня статистической значимости (критерий $\chi^{2}$ Пирсона $\left.(\mathrm{p}=0,00465)\right)$.

В группе больных детей достоверно чаще встречается разделенный тип семейной сплоченности, что говорит о более выраженной дистанцированности между членами семьи. В группе здоровых детей чаще встречается связанный тип семейной сплоченности, что говорит о более выраженной эмоциональной близости членов семьи и лояльности во взаимоотношениях, члены семьи часто проводят время вместе, и оно более важно, чем время, посвященное друзьям и интересам. Различия достигают уровня статистической значимости (критерий $\chi^{2}$ Пирсона $\left.(\mathrm{p}=0,00407)\right)$.

Таблица 1

Частота встречаемости различных типов семейной адаптации в группе больных детей и в группе здоровых детей

\begin{tabular}{|l|c|c|}
\hline \multicolumn{1}{|c|}{ Типы адаптации } & Группа больных детей & Группа здоровых детей \\
\hline Хаотичный & $60(53,6 \%)$ & $37(33 \%)$ \\
\hline Гибкий & $37(33 \%)$ & $42(37,5 \%)$ \\
\hline Структурный & $12(10,7 \%)$ & $23(20,5 \%)$ \\
\hline Ригидный & $3(2,7 \%)$ & $10(9 \%)$ \\
\hline \multicolumn{1}{|c|}{ Всего } & 112 & 112 \\
\hline
\end{tabular}

Таблица 2

Частота встречаемости различных типов семейной сплоченности

в группе больных детей и в группе здоровых детей

\begin{tabular}{|l|c|c|}
\hline \multicolumn{1}{|c|}{ Типы сплоченности } & Группа больных детей & Группа здоровых детей \\
\hline Разобщенный & $25(22,3 \%)$ & $23(20,5 \%)$ \\
\hline Разделенный & $52(46,4 \%)$ & $33(29,5 \%)$ \\
\hline Связанный & $15(13,4 \%)$ & $37(33 \%)$ \\
\hline Сцепленный & $20(17,9 \%)$ & $19(17 \%)$ \\
\hline \multicolumn{1}{|c|}{ Всего } & 112 & 112 \\
\hline
\end{tabular}


В ходе исследования нами были уточнены особенности взаимосвязи таких факторов, как статус семьи, семейная сплоченность и адаптация с функциональной диспепсией у детей 8-12 лет. Сравнение особенностей семейной адаптации и семейной сплоченности в группах: здоровые дети из полных семей, здоровые дети из неполных семей, больные дети из полных семей и больные дети из неполных семей показало, что семейные сплоченность и адаптация достоверно различаются во всех сравниваемых группах (критерий Крускала-Уоллиса $\quad(\mathrm{p}=0,001))$. Наиболее ярко семейные сплоченность и адаптация различаются в группах детей из полных семей по сравнению с детьми из неполных семей.

Полные семьи как больных, так и здоровых детей имели разделенный тип сплоченности. Неполные семьи как больных, так и здоровых детей имели разобщенный тип сплоченности. Полные семьи имеют разделенный тип сплоченности, но семьи с больными детьми имеют более низкие показатели этого типа, и эти различия достоверны (критерий КрускалаУоллиса $(\mathrm{p}=0,001))$. Неполные семьи имеют разобщенный тип семейной сплоченности, но семьи больных детей имеют более низкие показатели семейной сплоченности по сравнению со здоровыми, эти различия достоверны (критерий Крускала-Уоллиса $(\mathrm{p}=0,001))$.

В полных семьях как больных, так и здоровых детей семейная адаптация относится к структурному типу. В неполных семьях как больных, так и здоровых детей более выражена склонность к хаотичности (критерий КрускалаУоллиса $(\mathrm{p}=0,001))$. Фактор болезни усиливает выраженность неконструктивных форм адаптации в неполных семьях и конструктивных форм адаптации в полных семьях.

На основании полученных результатов нами были сформулированы следующие выводы.

Неблагоприятное функционирование семьи, неконструктивные формы семейных сплоченности и адаптации дестабилизируют развитие личности и способствуют возникновению функциональной диспепсии у детей 8-12 лет.

Семьи детей с функциональной диспепсией обладают более высокой степенью адаптации, чем семьи здоровых детей. Это обусловлено стремлением семейной системы приспосабливаться к новым условиям взаимодействия членов семьи в ситуации болезни.

Статус семьи тесно связан с формой семейной адаптации: неполные семьи имеют неконструктивные способы семейной адаптации, полные семьи имеют более конструктивные способы семейной адаптации. Фактор болезни усиливает выраженность неконструктивных форм адаптации в неполных семьях и конструктивных форм адаптации в полных семьях.

На основе полученных результатов была разработана коррекционная развивающая программа, направленная на оптимизацию несбалансированного типа семейных отношений. В настоящее время данная программа апробируется на базе городской больницы № 3 города Курска.

\section{ЛИТЕРАТУРА}

1. Александер $\Phi$. Психосоматическая медицина - М. : Изд-во «ЭКСМО-Пресс», 2002. - 352 с.

2. Андреева Г.В. Семейная психология. - СПб., 2004. - 285 c.

3. Бороздина Л.В., Былкина Н.Д. «Триада риска» у пациентов с дуоденальной язвой // Психол. журн. 2002. - № 2. - С. 65-78.

4. Боуэн М. О дифференциации «Я»// Московский психотерапевтический журнал. - 2005. - № 2. C. 147-164.

5. Бройтигам В., Кристиан П., Рад М. Психосоматическая медицина: кратк. учебн. / пер. с нем. Г.А. Обухова, А.В. Брунека; Предисл. В.Г. Остроглазова. - М. : ГЭОТАР-МЕДИЦИНА, - 1999. $376 \mathrm{c}$.

6. Варга А.Я. Системная семейная психотерапия. Краткий лекционный курс. - СПб. : Речь, 2001. $144 \mathrm{c}$.

7. Винникотт Д.В. Семья и развитие личности. Мать и дитя. - Екатеринбург : Литур, 2004. - 400 с.

8. Добряков И.В. Перинатальная психология. - СПб. : Питер-Юг, 2011. - 302 с.

9. Журавлев А.Л., Воловикова М.И., Галкина Т.В. Психологическое здоровье личности и духовнонравственные проблемы современного российского общества. - М. : Когито-Центр, 2014. - 318 с.

10. Исаев Д.Н. Эмоциональный стресс, психосоматические и соматопсихические расстройства у детей. - СПб. : Речь, 2005. - 400 с.

11. Лифинцева А.А. Влияние межличностных факторов на психосоматическое здоровье подростков // Вопросы психологии. - 2013. - № 4. - С. 34-45.

12. Минухин C., Фишман Ч. Техники семейной терапии / пер. с англ. А.Д. Иорданского. - М. : Независимая фирма «Класс», 1998. - 304 с.

13. Мясищев В.Н. Психология отношений: Избранные психологические труды / под ред. А.А. Бодалева М. : МПСИ; Воронеж : НПО «МОДЭК», 2004. $400 \mathrm{c}$.

14. Никольская И.М., Грановская Р.М. Психологическая защита у детей. - СПб. : Речь. - 2006. - 342 с.

15. Сатир В. Психотерапия семьи. - СПб.: Речь. 2000. $-337 \mathrm{c}$.

16. Фетисова А.С., Хмелевская И.Г. Взаимосвязь семейных оценочных отношений, самооценки и тревожности с функциональной диспепсией у детей 8-12 лет // Курский научно-практический вестник 
«Человек и его здоровье». - 2015. - № 4. C. $128-133$.

17. Фрейд 3. Два детских невроза. - М. : Изд. Фирма СТД, 2007. - 342 с.

18. Чернышев А.С., Сурьянинова Т.И. Генезис группового субъекта деятельности // Психол. журн. 1990. - T. 11, № 2. - С. 7-15.
19. Эйдемиллер Э.Г., Юстицикис В. Психология и психотерапия семьи. - СПб. : Питер, - 2008. - 672 с.

20. Энциклопедия психологических тестов. - М. : ТЕРРА - Книжный клуб, 2000. - 399 с. 